GANIT J. Bangladesh Math. Soc. (ISSN 1606-3694) 34 (2014) 89-100

\title{
STUDY OF INVENTORY MODEL FOR DETERIORATING ITEMS WITH EXPONENTIAL DEMAND FUNCTION
}

\author{
Manik Mondal ${ }^{1}$, Dr. Mohammed Forhad Uddin ${ }^{2}$, Kazi Anowar Hussain ${ }^{3}$ \\ ${ }^{1,3}$ Senior Lecturer in Mathematics, Basic Science Division, World University of Bangladesh. \\ ${ }^{2}$ Associate Professor, Department of Mathematics, BUET, Dhaka, Bangladesh. \\ Email: manik.ru.bd@gmail.com
}

Received 12.10.2014 Accepted 11.01.2015

\begin{abstract}
This paper develops an inventory model for deteriorating items consisting the ordering cost, unit cost, opportunity cost, deterioration cost and shortage cost. In this inventory model instead of linear demand function nonlinear exponential function of time for deteriorating items with deterioration rate has been considered. The formulated model has numerically solved by bisection method. The effects of inflation and cash flow are also taken into account under a trade-credit policy of discount with time. In order to validate the model, numerical examples have been solved by bisection method using Matlab. Further, the sensitivity of different parameters is considered in order to estimate the cash flow.
\end{abstract}

Keywords: Inventory, Deterioration, Non-linear demand, Inflation, Trade-credit policy

\section{Introduction and Outline of the Paper}

Inventory is quantity or store of goods that is held for some purpose or use. There are many variations of free cash flow but recently we have been asked a couple of times why we don't include change in working capital. So let us go through why we don't believe including changes to working capital is necessary to the feel cash flow calculation or for stock valuation for impacts the cash flow statement.

The reason why it should be considered as a liability is that the amount of accounts receivables is really just an interest free loan to the customer. The company has not received the cash for the bills. The working capital change on the balance sheet impacts the cash flow statement. Inventory is another major component of working capital and can also be considered to be a liability while accounts payable will add to positive cash flow because it's money that you owe but haven't paid yet. The ordering cost (also called setup costs, especially when producers are concerned), or cost of replenishing inventory, covers the friction created by orders themselves, that is, the costs incurred every time you place an order. The unit cost is the cost incurred by a company to produce, store and sell one unit of a particular product. The Opportunity cost of an alternative that must be forgone in order to pursue a certain action. Put another way, the benefits you could have received by taking an alternative action. Deterioration cost is that cost which is incurred by company on any assets due to small wear and tear in asset due to use. An economic shortage is a disparity between the amount demanded for a product or service and the amount supplied in a market. Specifically, a shortage occurs when there is excess demand; therefore, it is the opposite of a surplus. 
Supply Chain Management (SCM) is an essential element to operational efficiency. SCM can be applied to customer satisfaction and company success, as well as within common settings, including medical missions; disaster relief operations and other kinds of emergencies; cultural evolution; and it can help improve quality of life. Because of the vital role SCM plays within organizations, employers seek employees with loads of SCM skills and knowledge. The World is one big supply chain. SCM touches major issues, including the rapid growth of multinational corporations and strategic partnerships; global expansions and sourcing; fluctuating gas prices and environmental concerns, each of these developing trends, supply chain management is the most critical business discipline in the world today. Clearly, the impact that SCM has on business is significant and exponential. SCM impacts customer service by making sure the right product assortment and quantity are delivered in a timely fashion.

In addition, those products must be available in the location that customers expect. Customers should also receive quality after sale customer support. SCM has a tremendous impact on the bottom line. Firm's value supply chain managers because they decrease the use of large fixed assets such as plants, warehouses and transportation vehicles in the supply chain. Also, cash flow is increased because if delivery of the product can be expedited, profits will also be received quickly. SCM helps streamline everything from day-to-day product flows to unexpected natural disasters

Deterioration of physical goods is one of the important factors in any inventory and production system. The deteriorating items with shortages have received much attention of several researches in the recent year because most of the physical goods undergo decay or deterioration over time. Commodities such as fruits, vegetables and food stuffs from reduction by direct spoilage trick kept in store. The demand function relates price and quantity. It tells how many units of a good will be purchased at different prices. In general, at higher prices, less will be purchased. Thus, the graphical representation of the demand function has a negative slope. The market demand function is calculated by adding up all of the individual consumers' demand functions.Economic order quantity (EOQ) model is the method that provides the company with an order quantity. By using this model, the companies can minimize the costs associated with the ordering and inventory holding. In 1913, Ford W. Harris developed this formula whereas R. H. Wilson is given credit for the application and in-depth analysis on this model.

EOQ and EPQ are the model that are used to calculate the optimal quantity that can be purchased or produced to minimize the cost of both the carrying inventory and the processing of purchase orders or production set-ups. Basu, et al. [1] proposed a general inventory model with due consideration to the factors of time dependent partial backlogging and time dependent deterioration. Sharma, et al. [2] developed an inventory model for deteriorating items, the rate of deterioration follow the Weibull distribution with two parameters. The demand rate assumed of time dependent. The shortages are allowed and shortages are completely backlogged. Ghare and Schrader [3] developed a model for an exponentially decaying inventory. Inventory models with a time dependent 
rate of deterioration were considered by Covert and Philip [4], Mishra [5] and Deb and Chaudhuri [6]. In this model, shortages are completely backlogged.

In developing mathematical inventory model, it is assumed that payments will be made to the supplier for the goods immediately after receiving the consignment. One such trade credit policy is " $\alpha / T_{1}$ net $T^{\prime}$ which means that a $\alpha \%$ discount on sale price is granted if payments are made within $T_{1}$ days and the full sale price is due within $T\left(>T_{1}\right)$ days from the date of invoice if the discount is not taken". Ben-Horim and Levy [7], Chung [8], Aggarwal and Jaggi [9], etc., discussed trade-credit policy of type " $\alpha / T_{1}$ net $T$ " in their models. Aggarwal et al. [10] discussed an inventory model taking into consideration inflation, time-value of money and a trade credit policy " $\alpha / T_{1}$ net $T^{\prime \prime}$ with a constant demand rate. Lal and Staelin [11] developed an optimal discounting pricing policy. Sensitivity of the optimal solution is examined to see how far the output of the model is affected by changes in the values of its input parameters.

The paper is organized as follows. We introduce several elementary properties of the stationary inventory process and literature review in Section 1. We describe the mathematical formulation of your problem and solve it in Section 2. In Section 3 we present the numerical and graphical description of your results. Finally, in Section 4, we summarize the results and propose some directions for future research.

\section{Mathematical Formulation}

The exponential function has the form:

$$
D(t)=b \rho^{t}
$$

Where $b \neq 0$ and $\rho$ is a constant called the base of the exponential function. $\rho>$ 0 a $\quad \rho \neq 1, t$ is the independent variable. It is the exponent of the constant, $b$. Thus exponential functions have a constant base raised to a variable exponent. In economics exponential functions are important when looking at growth or decay. For examples are the value of an investment that increases by a constant percentage each period, sales of a company that increase at a constant percentage each period, models of economic growth or models of the spread of an epidemic.
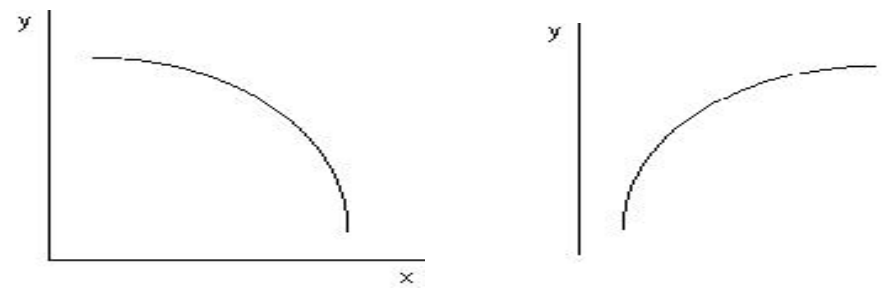

Notice that as the value of $x=t$ increases, the value of $y=D(t)$ increases or decreases more and more rapidly.

In this section, notation, assumptions of the various parameters, formulated the model and solve it. A deterministic order-level model with an infinite rate of replenishment is developed with the following notations and assumptions. 
Table1.1 Notation for the inventory and cost system

\begin{tabular}{|c|c|l|}
\hline $\mathrm{D}(\mathrm{t})$ & $:$ & $b \rho^{c},(b>0,0>\rho>1)$ is the demand rate at any time $\mathrm{t}$ \\
\hline $\mathrm{T}$ & $:$ & Cycle length \\
\hline$Q_{t}$ & $:$ & Order quantity in the (i+1)th cycle \\
\hline $\mathrm{I}$ & $:$ & Inventory Carrying charge \\
\hline $\mathrm{C}(\mathrm{t})$ & $:$ & Unit cost of the item at any time $\mathrm{t}$ \\
\hline $\mathrm{A}(\mathrm{t})$ & $:$ & Ordering cost of the item at any time t \\
\hline $\mathrm{h}$ & $:$ & Inflation rate per unit time \\
\hline $\mathrm{r}$ & $:$ & Opportunity cost per unit time \\
\hline$\theta$ & $:$ & Rate of deterioration $0 \leq \theta<1$ \\
\hline
\end{tabular}

Mathematically $D^{\prime}(t)=\frac{a(t)}{a}>0$

And $D^{\prime \prime}(t)=\frac{a^{2} \nu(\tau)}{d \tau^{2}} \leq 0$

Thus marginal demand is a decreasing function of time.

\section{Assumptions}

1. Lead time is zero.

2. Shortages are not allowed.

3. Replenishment is instantaneous.

4. The time horizon of the inventory system is infinite.

Let $A(t)$ and $C(t)$ be the ordering cost and unit cost of the item at any time t. Then $A(t)=A(0) e^{h t}$ and $C(t)=C(0) e^{h t}$, assuming continuous compounding of inflation.

Let $l_{i}(t)$ be the instantaneous inventory level at any time $t$ in the $(i+1) t h$ cycle. The differential equation governing the instantaneous states of $l_{i}(t)$ in the interval $[i],(i+$ 1) $T]$ is

$$
\frac{d l_{i}(t)}{d}+\theta l_{i}(t)=b \rho^{t}, i^{\prime} \leq t \leq(i+1) T
$$

where $l_{i}\left(i_{i}\right)=Q_{i}$ and $l_{i}((i+1) T)=0, \mathrm{i}=0,1,2 \ldots$

from equation (2.1) we get

$$
I_{i}(t)=\frac{l}{\theta+l c} \frac{b \rho^{t}}{\log \rho}+e^{-\theta} C_{i}
$$

When $I_{i}\left(i_{i}\right)=Q_{i}$ then $C_{i}=\left(Q_{i}-\frac{b \rho^{i}}{\theta+l i}\right) e^{i !}$

$$
\begin{gathered}
\text { When } I_{i}((i+1) T)=0 \text { then } Q_{i}=\frac{b}{\theta+\mathrm{l} i}\left[\rho^{i^{i}}-\rho^{(i+1) T} e^{\theta}\right] \\
\therefore I_{i}(t)=\frac{b}{\theta+\log \rho}\left[\rho^{t}-\rho^{i_{i}} e^{\left(i_{i}-t\right) \theta}\right]+Q_{i} e^{\left(i_{i}-t\right) \theta} \\
i^{\prime} \leq t \leq(i+1) T, i=0,1,2, \ldots
\end{gathered}
$$


Let $t_{0}, t_{1}, t_{2}, \ldots$ be the replenishment points and $t_{i+1}-t_{i}=T$ so that

$$
t_{i}=i T, \mathrm{i}=0,1,2,3 \ldots
$$

Here purchases made at time $t_{i}$ are paid after $M_{i}$ days and purchase price in real terms for $Q_{i}$ units at time $t_{i}$ in the $(i+1)$ th cycle is $Q_{i}(1-\alpha) C\left(t_{i}\right) e^{-h M_{1}}$

The present worth of cash-flows for the (i+1)-th cycle is

$$
\begin{aligned}
P_{i}{ }^{(d)}(T)=\left[A\left(t_{i}\right)\right. & +Q_{i} C\left(t_{i}\right)(1-\alpha) e^{-h M_{1}} \\
& \left.+I \prime\left(t_{i}\right)(1-\alpha) e^{-h M_{1}} \int_{i^{i}}^{(i+1) T} I_{i}(t) e^{-r} d\right] e^{-T t_{i}}=A_{1}+A_{2}+A_{3}, S i
\end{aligned}
$$

Where $A_{1}=A\left(t_{i}\right) e^{-r t_{i}}=A(0) e^{-i l} \quad ;\left(\right.$ assuming $R=r-h$ and using $\left.t_{i}=i_{i}\right)$,

$$
\begin{gathered}
A_{2}=Q_{i} C\left(t_{i}\right)(1-\alpha) e^{-h M_{1}} e^{-r t_{i}} \\
\Rightarrow A_{2}=\frac{b(0)(1-\alpha) e^{-h M_{1}}}{\theta+l i} \rho^{i_{i}} e^{-i i}-\frac{b(0)(1-\alpha) e^{-h M_{1}}}{\theta+l i} \rho^{(i+1) T} e^{-i i} e^{\theta} \\
\left.A_{3}=I^{\prime}\left(t_{i}\right)(1-\alpha) e^{-h M_{1}} \int_{i^{\prime}}^{(i+1) T} I_{i}(t) e^{-r} d\right] e^{-r t_{i}}
\end{gathered}
$$

Now,

$$
\begin{array}{rl}
\int_{i_{i}}^{(i+1) I} l_{i}(t) e^{-r} & d \\
& =\frac{b\left(e^{-(I+\theta) T}-1\right)}{(\theta+\log \rho)(r+\theta)} \rho^{i_{i}} e^{-i_{i}}+\frac{b\left(\rho^{T} e^{-r}-1\right)}{(\theta+\log \rho)(\log \rho-r)} \rho^{i^{i}} e^{-i_{i}} \\
& -\frac{b\left(e^{-(r+\theta) T}-1\right)}{(\theta+\log \rho)(r+\theta)} \rho^{i_{i}} e^{-i_{i}}+\frac{b\left(e^{-r}-e^{\theta}\right)}{(\theta+\log \rho)(r+\theta)} \rho^{(i+1) T} e^{-i_{1}}
\end{array}
$$

Therefore, , taking $\mathrm{P}=2 r-h$

$$
\begin{aligned}
P V_{i}^{(d)}(T)=A(0) e^{-i i}+\frac{b(0)(1-\alpha) e^{-n M_{1}}}{\theta+\log \rho} \rho^{i_{i}} e^{-i i} & \\
& -\frac{b(0)(1-\alpha) e^{-h M_{1}}}{\theta+\log \rho} \rho^{(i+1) T} e^{-i i} e^{\theta} \\
& +I\left(( 0 ) ( 1 - \alpha ) e ^ { - h M _ { 1 } } \left\lfloor\frac{b\left(\rho^{T} e^{-r}-1\right)}{(\theta+\log \rho)(\log \rho-r)} \rho^{i^{i}}\right.\right. \\
& \left.+\frac{b\left(e^{-r}-e^{\theta}\right)}{(\theta+\log \rho)(r+\theta)} \rho^{(i+1) T}\right] e^{-i i}
\end{aligned}
$$

The present worth of all future cash flows is

$$
P V_{\infty}^{(d)}(T)=\sum_{i=0}^{\infty} P_{i}{ }^{(d)}(T)
$$

So

$$
P V_{\infty}^{(d)}(T)=A(0) \frac{1}{1-e^{-R}}+\frac{b(\mathrm{U})(1-u) e^{-h M_{1}}}{\theta+\mathrm{lc} \rho} \frac{1}{\left(1-\rho^{T} e^{-R}\right)}-\frac{b(\mathrm{U})(1-u) e^{-h M_{1}}}{\theta+\mathrm{l} \rho} \frac{\rho}{\left(1-\rho^{T} e^{-R}\right)} e^{\theta}
$$




$$
+\frac{b \quad(0)(1-\alpha) e^{-h M_{1}}}{(\theta+\log \rho)(\log \rho-r)} \frac{\left(\rho^{T} e^{-r}-1\right)}{\left(1-\rho^{T} e^{-P}\right)}+\frac{\rho(0)(1-\alpha) e^{-h M_{1}}}{(\theta+\log \rho)(r+\theta)} \frac{\left(e^{-r}-e^{\theta}\right)}{\left(1-\rho^{T} e^{-P}\right)}
$$

The solution of the equation $\frac{d P \underset{\alpha}{(d)}(T)}{d}=0$ gives the optimum value of $\mathrm{T}$ provided it satisfies the condition

$$
\frac{d^{2} P_{\infty}^{(d)}(T)}{d T^{2}}>0
$$

Now $\frac{d P_{\propto}^{(d)}(T)}{d}=0$ yields the equation

$$
\begin{aligned}
& -A(0) \frac{K e^{-R}}{\left(1-e^{-R}\right)^{2}} \\
& +\left[\frac{b(0)(1-\alpha)(\log \rho-K) e^{-h M_{1}}}{(\theta+\log \rho)}\right. \\
& \left.-\frac{\rho \quad(0)(1-\alpha)(\log \rho-K) e^{-h M_{1}} e^{\theta}}{(\theta+\log \rho)}\right] \frac{\rho^{T} e^{-R}}{\left(1-\rho^{T} e^{-R}\right)^{2}} \\
& -\frac{\rho \quad(0)(1-\alpha) e^{-h M_{1}}}{(\theta+\log \rho)} \frac{e^{\theta}}{\left(1-\rho^{I} e^{-R}\right)} \\
& +\frac{b \quad(0)(1-\alpha) e^{-h M_{1}}}{(\theta+\log \rho)(\log \rho-r)} \frac{\left(1-\rho^{T} e^{-P}\right)(\log \rho-r) \rho^{T} e^{-r}+\left(\rho^{T} e^{-r}-1\right)(\log \rho-P) \rho^{T} e^{-}}{\left(1-\rho^{I} e^{-P}\right)^{2}} \\
& -\frac{b \quad(0)(1-\alpha) e^{-h M_{1}}}{(\theta+\log \rho)(r+\theta)} \frac{\left(1-\rho^{I} e^{-P}\right)\left(r e^{-r}+\theta e^{\theta}\right)+\left(e^{-r}-e^{\theta}\right)(P-l \quad) \rho^{I} e^{-}}{\left(1-\rho^{I} e^{-P}\right)^{2}}
\end{aligned}
$$

This equation being highly nonlinear equationcannot be solved analytically. It can be solved numerically for given parameter values. Its solution gives the optimum $T^{*}$ quantities $Q_{i}^{*}(i=0,1,2 \ldots \ldots)$ from and $P_{\infty}^{(d)}(T)^{*}$, the optimum present value of all future cash flows from.

As commented before, this equation also needs to be solved numerically.

\section{Result, Discussion and Computation Analysis}

In this section, we consider to parameter numerical example to valid our model. Let $a=50, b=5, C(0)=10, r=0.04, I=0.02, A(0)=2000, M=30, h=0.02, \alpha=0.1$, $\theta=0.01, \rho=0.5$ in appropriate units. Solving the highly non-linear equation (2.10) by Bisection Method, we get the optimum value of Tas $T^{*}=170.978$. Substituting $T^{*}$ in equation (2.8), we get the optimum value of $P V_{\infty}^{(d)}(T)$ as $P V_{\infty}^{(d)}(T)^{*}=2170.407$.

Based on the numerical example considered above, a sensitivity analysis of $\mathrm{T}^{*}, V_{\infty}^{(d)}(T)^{*}, P V_{\infty}^{(w)}(T)^{*}$ is performed considering ten cases by changing (increasing or decreasing) the parameters by $10 \%$ and $50 \%$ and taking one parameter at a time, keeping the remaining parameters at their original values. 
Percentage Error: A measure of how inaccurate a measurement is, standardized to how large the measurement is. Found by the formula (measured value-actual value)/actual value* $100 \%$.

Table 1.2 Sensitivity of different parameters

\begin{tabular}{|c|c|c|c|c|c|}
\hline $\begin{array}{l}\text { Changing } \\
\text { parameters }\end{array}$ & $(\%)$ Change & $\mathrm{T}^{*}$ & $P_{\infty}^{(d)}(I)^{*}$ & $(\%)$ changein $\mathrm{T}^{*}$ & $\begin{array}{l}(\%) \text { changein } \\
P_{\infty}^{(d)}(T)^{*}\end{array}$ \\
\hline \multirow{10}{*}{$\mathrm{A}(0)$} & +50 & 183.983 & 3199.824 & +7.606 & +47.429 \\
\hline & +40 & 181.761 & 2994.528 & +6.307 & +37.971 \\
\hline & +30 & 179.378 & 2788.977 & +4.913 & +28.500 \\
\hline & +20 & 176.809 & 2583.135 & +3.411 & +19.016 \\
\hline & +10 & 174.023 & 2376.962 & +1.781 & +9.516 \\
\hline & -10 & 167.622 & 1963.404 & -1.963 & -9.538 \\
\hline & -20 & 163.882 & 1755.867 & -4.150 & -19.099 \\
\hline & -30 & 159.659 & 1547.681 & -6.620 & -28.691 \\
\hline & -40 & 154.808 & 1338.683 & -9.457 & -38.321 \\
\hline & -50 & 149.108 & 1128.639 & -12.791 & -47.999 \\
\hline \multirow{10}{*}{$\mathrm{b}$} & +50 & 158.121 & 2217.173 & +7.606 & +2.155 \\
\hline & +40 & 160.296 & 2208.453 & +6.307 & 1.752 \\
\hline & +30 & 162.639 & 2199.450 & +4.913 & 1.338 \\
\hline & +20 & 165.176 & 2190.134 & +3.411 & 0.909 \\
\hline & +10 & 167.941 & 2180.467 & +1.781 & 0.463 \\
\hline & -10 & 174.345 & 2159.899 & -1.963 & -0.484 \\
\hline & -20 & 178.119 & 2148.875 & -4.150 & -0.992 \\
\hline & -30 & 182.411 & 2137.246 & -6.620 & -1.527 \\
\hline & -40 & 187.381 & 2124.891 & -9.457 & -2.097 \\
\hline & -50 & 193.281 & 2111.643 & -12.791 & -2.707 \\
\hline \multirow{10}{*}{$\mathrm{C}(0)$} & +50 & 158.121 & 2217.173 & -7.519 & +2.155 \\
\hline & +40 & 160.296 & 2208.453 & -6.247 & 1.752 \\
\hline & +30 & 162.639 & 2199.450 & -4.876 & 1.338 \\
\hline & +20 & 165.176 & 2190.134 & -3.393 & 0.909 \\
\hline & +10 & 167.941 & 2180.467 & -1.776 & 0.463 \\
\hline & -10 & 174.345 & 2159.899 & 1.969 & -0.484 \\
\hline & -20 & 178.119 & 2148.875 & 4.177 & -0.992 \\
\hline & -30 & 182.411 & 2137.246 & 6.686 & -1.527 \\
\hline & -40 & 187.381 & 2124.891 & 9.594 & -2.097 \\
\hline & -50 & 193.281 & 2111.643 & +13.044 & -2.707 \\
\hline \multirow{9}{*}{$\mathrm{r}$} & +50 & 117.189 & 2056.495 & -31.459 & -5.248 \\
\hline & +40 & 124.884 & 2067.554 & -26.958 & -4.738 \\
\hline & +30 & 133.749 & 2082.018 & -21.773 & -4.072 \\
\hline & +20 & 144.082 & 2101.584 & -15.730 & -3.170 \\
\hline & +10 & 156.294 & 2129.201 & -8.587 & -1.898 \\
\hline & -10 & 189.029 & 2236.697 & 10.557 & 3.054 \\
\hline & -20 & 211.944 & 2355.637 & 23.960 & 8.534 \\
\hline & -30 & 242.767 & 2610.291 & 41.987 & 20.267 \\
\hline & -40 & 291.113 & 3397.790 & 70.263 & 56.550 \\
\hline
\end{tabular}




\begin{tabular}{|c|c|c|c|c|c|}
\hline $\begin{array}{l}\text { Changing } \\
\text { parameters }\end{array}$ & (\%)Change & $\mathrm{T}^{*}$ & $P_{\infty}^{(d)}(I)^{*}$ & $(\%)$ changein $\mathrm{T}^{*}$ & $\begin{array}{c}(\%) \text { changein } \\
P_{\infty}^{(d)}(T)^{*}\end{array}$ \\
\hline \multirow{10}{*}{ I } & +50 & 166.723 & 2189.464 & -2.489 & 0.878 \\
\hline & +40 & 167.528 & 2185.718 & -2.017 & 0.705 \\
\hline & +30 & 168.355 & 2181.940 & -1.533 & 0.531 \\
\hline & +20 & 169.205 & 2178.130 & -1.036 & 0.355 \\
\hline & +10 & 170.079 & 2174.286 & -0.525 & 0.178 \\
\hline & -10 & 171.903 & 2166.491 & 0.541 & -0.180 \\
\hline & -20 & 172.857 & 2162.537 & 1.099 & -0.362 \\
\hline & -30 & 173.842 & 2158.544 & 1.675 & -0.546 \\
\hline & -40 & 174.858 & 2154.509 & 2.269 & -0.732 \\
\hline & -50 & 175.909 & 2150.433 & 2.884 & -0.920 \\
\hline \multirow{10}{*}{ M } & +50 & 180.588 & 2142.073 & 5.620 & -1.305 \\
\hline & +40 & 178.660 & 2147.357 & 4.492 & -1.061 \\
\hline & +30 & 176.735 & 2152.827 & 3.367 & -0.809 \\
\hline & +20 & 174.813 & 2158.488 & 2.243 & -0.549 \\
\hline & +10 & 172.894 & 2164.346 & 1.120 & -0.279 \\
\hline & -10 & 169.065 & 2176.677 & -1.118 & 0.288 \\
\hline & -20 & 167.156 & 2183.162 & -2.235 & 0.587 \\
\hline & -30 & 165.250 & 2189.869 & -3.350 & 0.896 \\
\hline & -40 & 163.347 & 2196.805 & -4.462 & 1.216 \\
\hline & -50 & 161.449 & 2203.977 & -5.573 & 1.547 \\
\hline \multirow{10}{*}{$\mathrm{h}$} & +50 & 242.734 & 2378.502 & 41.968 & 9.588 \\
\hline & +40 & 224.212 & 2303.732 & 31.135 & 6.142 \\
\hline & +30 & 208.238 & 2253.154 & 21.792 & 3.812 \\
\hline & +20 & 194.277 & 2217.195 & 13.626 & 2.155 \\
\hline & +10 & 181.950 & 2190.633 & 6.417 & 0.931 \\
\hline & -10 & 161.142 & 2154.619 & -5.752 & -0.727 \\
\hline & -20 & 152.270 & 2142.042 & -10.941 & -1.306 \\
\hline & -30 & 144.226 & 2131.847 & -15.646 & -1.776 \\
\hline & -40 & 136.895 & 2123.462 & -19.933 & -2.162 \\
\hline & -50 & 130.186 & 2116.476 & -23.858 & -2.485 \\
\hline \multirow{10}{*}{$u$} & +50 & 172.803 & 2164.629 & 1.068 & -0.266 \\
\hline & +40 & 172.429 & 2165.795 & 0.848 & -0.212 \\
\hline & +30 & 172.060 & 2166.957 & 0.633 & -0.158 \\
\hline & +20 & 171.695 & 2168.112 & 0.419 & -0.105 \\
\hline & +10 & 171.334 & 2169.262 & 0.208 & -0.052 \\
\hline & -10 & 170.625 & 2171.545 & -0.206 & 0.052 \\
\hline & -20 & 170.277 & 2172.679 & -0.409 & 0.104 \\
\hline & -30 & 169.932 & 2173.807 & -0.611 & 0.156 \\
\hline & -40 & 169.591 & 2174.929 & -0.810 & 0.208 \\
\hline & -50 & 169.254 & 2176.048 & -1.008 & 0.259 \\
\hline
\end{tabular}




\begin{tabular}{|c|c|c|c|c|c|}
\hline $\begin{array}{c}\text { Changing } \\
\text { parameters }\end{array}$ & $(\%)$ Change & $\mathrm{T}^{*}$ & $P_{\infty}^{(d)}(T)^{*}$ & $(\%)$ changein $\mathrm{T}^{*}$ & $\begin{array}{c}(\%) \text { changein } \\
P_{\infty}^{(d)}(T)^{*}\end{array}$ \\
\hline & +50 & 137.388 & 2294.453 & -19.646 & 5.715 \\
& +40 & 142.936 & 2268.592 & -16.401 & 4.523 \\
& +30 & 148.985 & 2243.194 & -12.862 & 3.353 \\
$\theta$ & +20 & 155.611 & 2218.319 & -8.987 & 2.207 \\
& +10 & 162.904 & 2194.032 & -4.721 & 1.088 \\
& -10 & 179.974 & 2147.524 & 5.262 & -1.054 \\
& -20 & 190.080 & 2125.471 & 11.172 & -2.070 \\
& -30 & 201.544 & 2104.347 & 17.877 & -3.043 \\
& -40 & 214.712 & 2084.253 & 25.578 & -3.969 \\
& -50 & 230.092 & 2065.298 & 34.574 & -4.842 \\
\hline \multirow{5}{*}{$\rho$} & +50 & 130.301 & 2408.604 & -23.791 & 7.975 \\
& +40 & 139.160 & 2337.666 & -18.609 & 5.173 \\
& +30 & 147.433 & 2282.688 & -13.770 & 3.131 \\
& +20 & 155.374 & 2238.375 & -9.125 & 1.437 \\
& +10 & 163.171 & 2201.606 & -4.565 & -1.241 \\
& -10 & 178.942 & 2143.461 & 4.658 & -2.329 \\
& -20 & 187.219 & 2119.852 & 9.499 & -3.293 \\
& -30 & 195.993 & 2098.918 & 14.630 & -4.157 \\
& -40 & 205.507 & 2080.166 & 20.195 & -4.939 \\
\hline
\end{tabular}

We investigate how the input parameters change significantly the output parameters. We change in one parameter and keeping other parameters invariant. The base data are got accordingly to the numerical example. In Table 1.2, it is seen that the percentage change in $P{ }_{w}^{(d)}(T)^{*}$ is almost equal for both positive and negative changes of all the parameters except $A(0)$. It is somewhat more sensitive for a positive change than an equal negative change of parameter $A(0)$. Due to positive and negative percentage changes in parameters $b, C(0), l, h, \theta a$ pincreases and decreases respectively.But this trend is reversed for the parameters $r, M a \quad \alpha$.

Figure1 to figure 4 show the estimated significant values of the parameters ordering cost, unit cost, and opportunity cost and inflation rate.

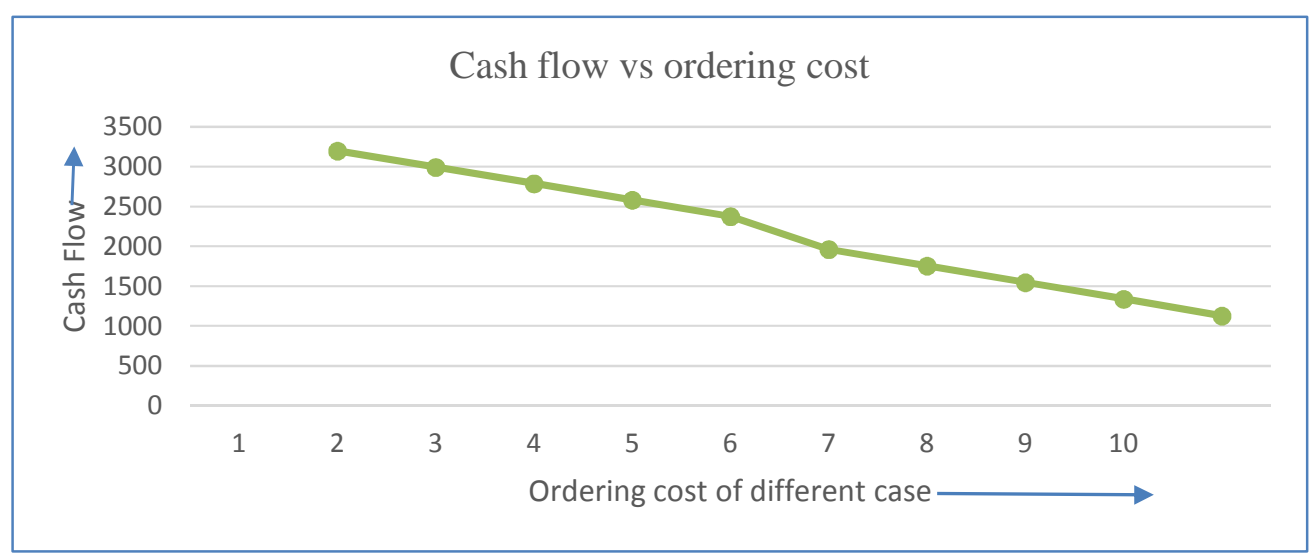

Fig. 1. Effect of ordering coston cash flow 


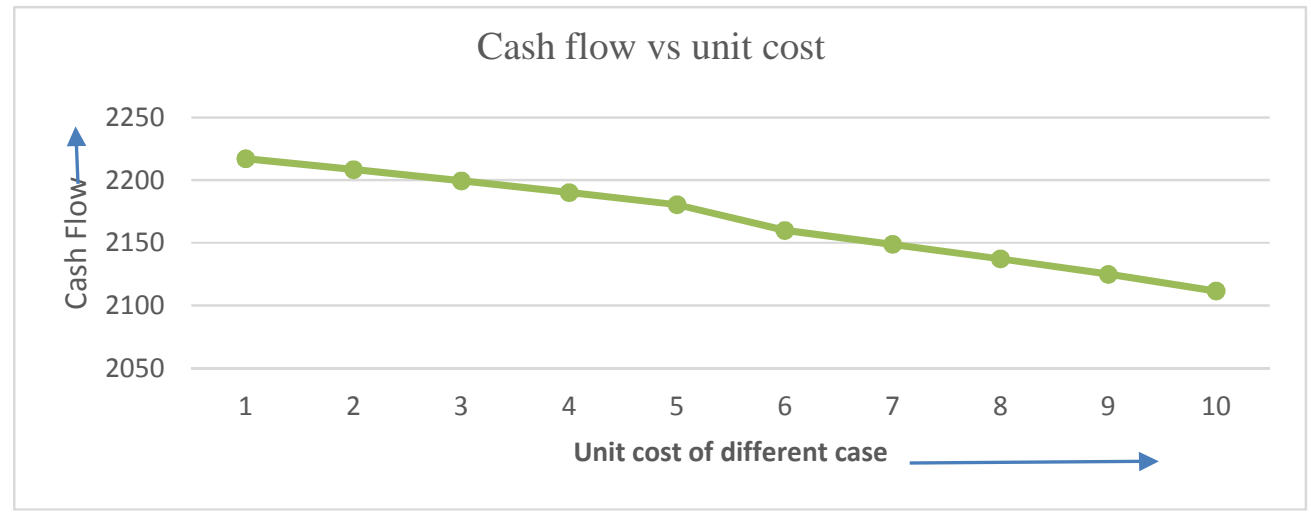

Fig. 2 Effect of unit costof cash flow

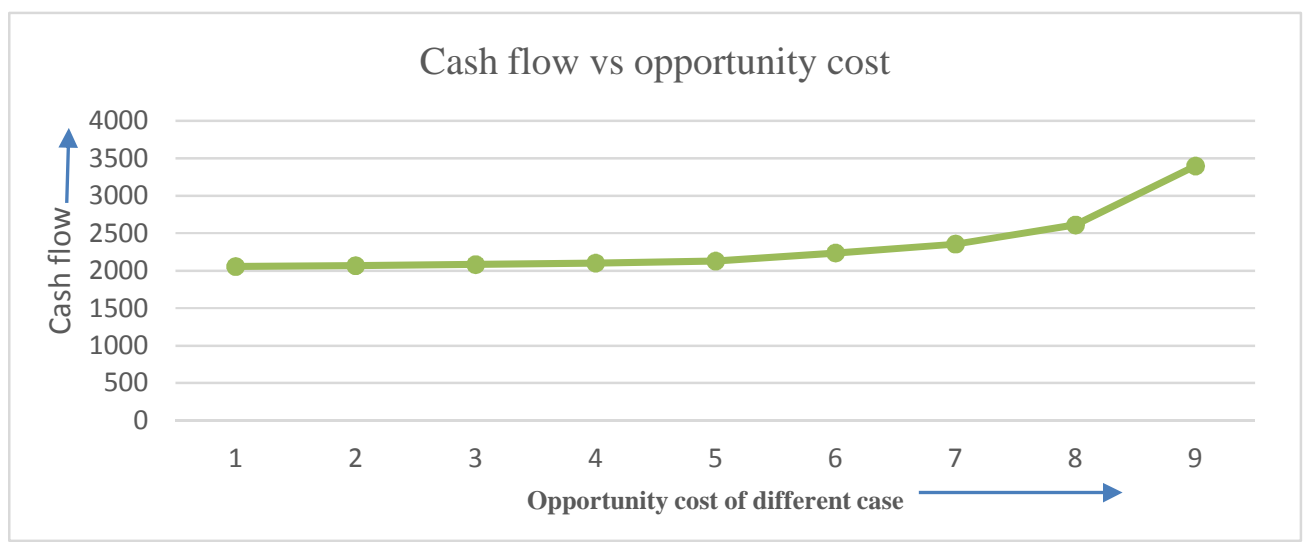

Fig. 3 Effect of opportunity cost on cash flow

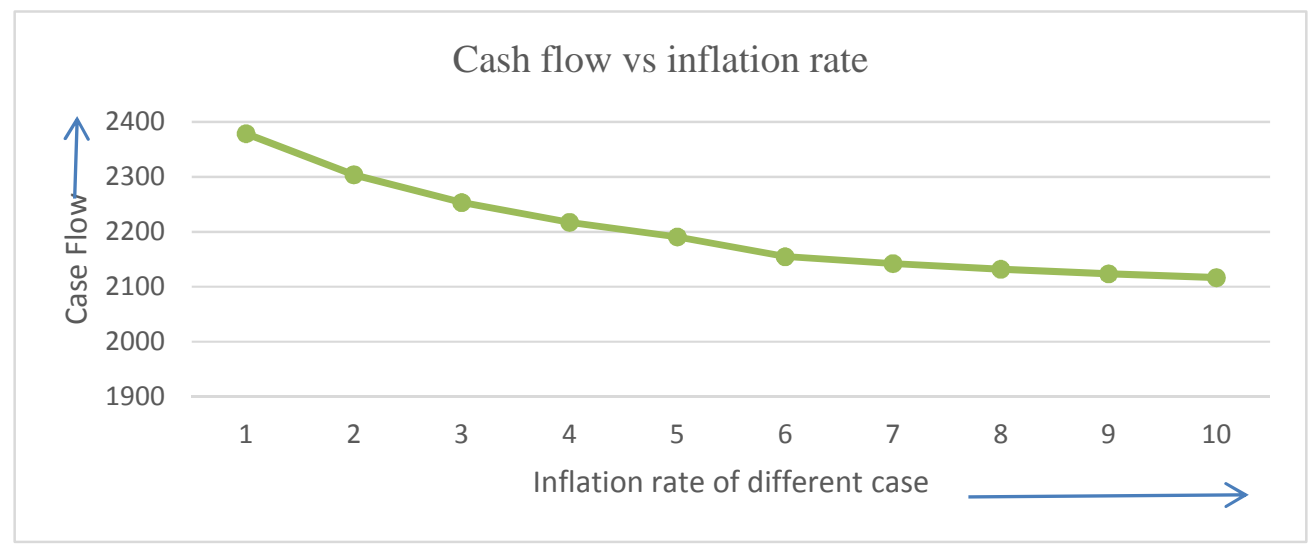

Fig. 4 Effect of inflation rate on cash flow

Figures1, 2 and 4 depict the cost decreases cash flow also decreases gradually. It is observed that if the cost decreases then the cash flow increases gradually (Figure 3). 
Further, from Figures 1, 2, 3, 4 and table 1.2, it is apparently clear that if economic order quantity decreases ordering cost, unit cost and inflation rate decreases but the opportunity cost increases.

\section{Conclusion}

The model deals with the optimum replenishment policy of deteriorating items in the presence of inflation and a trade credit policy. In this model instead of linear demand function, we have considered nonlinear exponential function. Numerical example, it is found that the optimum present worth of all future cash flows is $P V_{\mathrm{u}}^{(d)}(T)^{*}=$ 2170.407.Time dependent demand is applicable to thegoods whose demand changes steadily over time. Demand of a consumer goods changes steadily along with a steady change in the population density. A time-dependent demandrate is certainly more realistic than a constant demand rate

It is observed that there is no appreciable change in the optimum value of the present worth of all future cash flows for changes made in the value of deterioration rate and the cash flow decrease if the ordering cost, unit cost and inflation rate are decrease. On the other hand, the cash flow increase if opportunity cost decrease. Hence the discount is considered to be better economically.

This model can further be extended to varying deterioration, ramp type demand with finite rate of replenishment.

\section{Appendix}

Assuming $r>h$, we have

$$
\begin{aligned}
& \sum_{i=0}^{\infty} e^{-i j}= \frac{1}{1-e^{-R}}, \sum_{i=0}^{\infty} e^{-i l}=\frac{1}{1-e^{-P}}, \sum_{i=0}^{\infty} \rho^{i_{i}} e^{-i i}=\frac{1}{1-\rho^{I} e^{-R}}, \sum_{i=0}^{\infty} \mu^{i_{i}} e^{-i i} \\
&= \frac{1}{1-\rho^{I} e^{-P}} \\
& \sum_{i=0}^{\infty} \rho^{(i+1) T} e^{-i i}=\frac{\rho}{1-\rho^{I} e^{-R}}, \sum_{i=0}^{\infty} \rho^{(i+1) T} e^{-i l}=\frac{\rho}{1-\rho^{I} e^{-P}}
\end{aligned}
$$

\section{REFERENCES}

[1] Basu, M. and Sinha, S., An inflationary inventory model with time dependent demand with Weibull distribution deterioration and partial backlogging under permissible delay in payments, Control and Cybernetics, 36 (2007).

[2] Sharma, V. and Chaudhary, R.R., An inventory Model for deteriorating items with Weibull Deterioration with Time Dependent Demand and Shortages, Research Journal of Management Sciences, Vol. 2(3)March (2013), 28-30.

[3] Ghare, P.M. and Schrader, G.F., An inventory model for exponentially deteriorating items, Journal of Industrial Engineering, 14(1963), 238-243.

[4] Covert, R.P. and Philip, G.C., An EOQ model for items with Weibull distribution deterioration, AIIE Transactions, 5(1973), 323-326. 
[5] Mishra, R.B., Optimum production lot-size model for a system with deteriorating inventory, International Journal of Production Research, 3(1975), 495-505.

[6] Deb, M. and Chaudhuri, K.S., An EOQ model for items with finite rate of production and variable rate of deterioration, Operation research, 23(1986), 175-181.

[7] Ben-Horim, M., and Levy, H., Inflation and the trade credit period, Management Science, 28(6) (1982), 646-651.

[8] Chung, K.H., Inventory control and trade-credit revisited, Journal of Operational ResearchSociety, 4(5) (1989) 495-498.

[9] Aggarwal, S.P., and Jaggi, C.K., Credit financing in economic ordering policies of deteriorating items, International Journal of Production Economics, 34(1994), 151-155.

[10] Aggarwal, K.K., Aggarwal, S.P., and Jaggi, C.K., Impact of inflation and credit policies on economic ordering, Bull. Pure Appl. Sci., 16(1) (1997) ,93-100.

[11] Lal, R., and Staelin, R., An approach for developing an optimal discount pricing policy, Management Science, 30 (1994), 1524-1539. 